\title{
Thermal and Physical Properties of Crude Palm Oil with Higher Oleic Content
}

\author{
Erislene S. de Almeida ${ }^{1}$, Daniela da Silva Damaceno ${ }^{2}$, Laiane Carvalho ${ }^{1}$, Priscilla Araújo Victor ${ }^{1}$, \\ Rafaela Menezes dos Passos ${ }^{3}$, Paula Virginia de Almeida Pontes ${ }^{3}$, Marcílio Cunha-Filho ${ }^{4}$,, Klicia A. Sampaio ${ }^{3}(\mathbb{C}$ \\ and Simone Monteiro ${ }^{1, *(1)}$
}

check for

updates

Citation: de Almeida, E.S.;

da Silva Damaceno, D.; Carvalho, L.;

Victor, P.A.; dos Passos, R.M.;

de Almeida Pontes, P.V.; Cunha-Filho, M.;

Sampaio, K.A.; Monteiro, S. Thermal and Physical Properties of Crude Palm Oil with Higher Oleic Content. Appl. Sci. 2021, 11, 7094. https:// doi.org/10.3390/app11157094

Academic Editor: Ewa Ostrowska-Ligęza

Received: 9 March 2021

Accepted: 15 April 2021

Published: 31 July 2021

Publisher's Note: MDPI stays neutral with regard to jurisdictional claims in published maps and institutional affiliations.

Copyright: (C) 2021 by the authors. Licensee MDPI, Basel, Switzerland. This article is an open access article distributed under the terms and conditions of the Creative Commons Attribution (CC BY) license (https:/ / creativecommons.org/licenses/by/ $4.0 /)$.
1 Institute of Chemistry, University of Brasilia, Brasilia 70910-000, Brazil; erislene.almeida@gmail.com (E.S.d.A.); laiane.carvalho001@gmail.com (L.C.); pri.victor311085@gmail.com (P.A.V.)

2 Faculty of Chemical Engineering, University of Campinas, Campinas 13083-852, Brazil; ddsdamaceno@gmail.com

3 Faculty of Food Engineering, University of Campinas, Campinas 13083-000, Brazil; rafaelamenezes.ps@gmail.com (R.M.d.P.); paulapontes15@gmail.com (P.V.d.A.P.); klicias@unicamp.br (K.A.S.)

4 Faculty of Health Sciences, University of Brasilia, Brasilia 70910-000, Brazil; marcilio@unb.br

* Correspondence: simonems@unb.br; Tel.: +55-(61)-3107-3830

\begin{abstract}
Interspecific hybridization of oil palms (E. guineensis $\times$ E. oleifera) was initially exploited to provide disease resistance and, consequently, increased oleic acid content. Besides the growing importance of this cultivar to the market, there is little information about this oil's properties. In this context, this study aimed to determine a comprehensive physicochemical and thermal characterization of hybrid palm oil (HOPO) compared with the better-known African palm oil (APO). Differences in the distribution of fatty acids, carotenoids, and tocols were observed. Minor differences in density and viscosity were found between the oils, with no relevance for the materials' processing design. Nevertheless, HOPO showed unique crystallization behavior, which potentially can affect industrial operations, such as fractionation. HOPO did not present the two thermal characteristic regions of $\mathrm{APO}$, attributed to olein and stearin fractions. The HOPO demonstrated a decrease in the melting point of more than $3{ }^{\circ} \mathrm{C}$ in relation to $\mathrm{APO}$, and a reduction in the crystallization point of more than $6{ }^{\circ} \mathrm{C}$. Furthermore, besides the higher content of unsaturated fatty acids, HOPO was more stable than APO due to a higher antioxidant content. These results could be useful to establish operation conditions for processes using palm oil from hybrid oil palm.
\end{abstract}

Keywords: crude palm oil; interspecific hybridization; melting; crystallization; carotenes

\section{Introduction}

Palm oil has great importance in the world economic scenario, being the most used vegetable oil source. In fact, according to the United States Department of Agriculture, in 2020, palm oil world production was 75 million tons [1], surpassing the production of soybean, sunflower, and canola oil and accounting for one-third of vegetable oil production [2]. It has a wide application in industries, especially in food and pharmaceutical industries [3], also being one of the main alternatives for biofuel production in the following years [4].

Most commercial oil palms used are obtained from E. guineensis, an African species with high productivity per hectare, though very susceptible to fatal yellowing disease [5]. Alternatively, E. oleifera, an oil palm native from Central and South America, shows high resistance to this disease and other pests; however, it is not commercially exploited due to its low productivity. In this sense, the hybridization between both species (E. guineensis $\times$ E. oleifera) can generate an oil palm as productive as the African species and resistant to diseases like the American species [6].

Besides the disease resistance, hybridization also changes palm oil's chemical composition. Palm oil extracted from a hybrid cultivar showed an intermediary fatty acids profile 
compared to its two parental species [7]. Commonly, E. guineensis oil presents about 50\% of saturated fatty acids, i.e., $44 \%$ of palmitic, $5 \%$ stearic, and traces of myristic, in addition to unsaturated fatty acids which correspond to approximately $40 \%$ oleic and $10 \%$ linoleic acids [8]. Regarding E. guineensis $\times$ E. oleifera oil, the fatty acids profile corresponds mainly to oleic $(56 \%)$, palmitic $(27 \%)$, linoleic $(11 \%)$, and stearic $(3.5 \%)$ acids [6]. The Codex Committee on Fats and Oils recommends commercializing such oil with the denomination of palm oil with higher oleic content [9].

In the literature, there are several studies regarding hybrid oil palm trees and their oils' characterization. The studies describe the cultivar's growth and its vegetative characteristics and characterization regarding oil composition in terms of fatty acids, acylglycerols, and minor compounds [5,7,8,10-12]. All those previously mentioned studies regard chemical composition and fatty acid profile. However, there is a lack of scientific studies on the processing and physical properties of palm oil from the hybrid cultivar.

Undeniably, the fatty acid profile determination assumes great importance since it is related to vegetable oils' physical properties. The wide range of food and non-food applications is due to palm oil's unique fatty acid composition, which allows its easy fractionation [13-15]. Under controlled thermal conditions, palm oil can be fractionated into two components in a single step: a solid fraction (stearin, which contains more trisaturated triacylglycerol and will crystallize) and a liquid fraction (olein, which contains less trisaturated triacylglycerol, remaining liquid) $[2,13]$.

This fractionation process can determine some of the chemical and physical properties of the oleins and stearins produced. In the food industry, those two fractions have different applications; for instance, olein may be used as frying oil and stearin as a butter substitute [16]. Each fraction's yield highly depends on the triacylglycerol composition and palm oil's crystallization behavior $[13,17,18]$. Besides, fatty acids also play an important role in terms of their effects on human health. An oil with a high content of monounsaturated fatty acids, such as oleic acid, can lower bad cholesterol levels and protect against heart disease [5,6]. On the other hand, saturated fatty acids, such as palmitic acids, are related to a higher incidence of cardiovascular diseases and obesity $[7,8]$. African palm oil (APO) has a balanced composition between saturated and unsaturated fatty acids; hybrid palm oil (HOPO), in turn, has a high content of unsaturated fatty acids, especially oleic acid [9] Furthermore, palm oil is widely used in non-food industries, including its application other than food as hydraulic oil, drilling fluid, transmission fluid and lubricants, being fully biodegradable [19].

Several physical properties which infer process design also depend on the fatty acid composition. For instance, density and viscosity, essential fluid properties for the design of pipes, accessories, and equipment utilized in the oil industry, are highly dependent on the length and degree of fatty acids' unsaturation [20,21]. The composition of fatty acids attached to a triacylglycerol molecule determines its thermal behavior. The different molecular structures of triacylglycerols, with their different chemical characteristics, manifest their physical states at different temperatures, giving the oil crystallization and melting behavior [18]. The more saturated the fatty acids adhered to the triacylglycerol, the faster the crystallization processes. Besides the importance of palm oil for the industry and the growing interest in cultivating hybrid oil palms, there is a lack of physical and thermal properties for palm oils with higher oleic content.

In this context, this work aims to determine the physicochemical and thermal properties of commercial hybrid palm oil obtained from an interspecific hybrid cultivar (E. oleifera $\times$ E. guineensis). The results were compared to the better-known and widely commercially exploited African palm oil (E. guineensis).

\section{Material and Methods}

\subsection{Physicochemical Characterization}

Commercial crude oils obtained from two different oil palms-Elaeis guineensis and the interspecific hybridization of Elaeis guineensis $\times$ Elaeis oleifera, here so-called African 
(APO) and hybrid palm oil (HOPO), respectively—were kindly supplied by Denpasa (Santa Bárbara do Pará, Brazil). The oil samples were characterized regarding standard quality parameters, following the AOCS official methods [22]: iodine value and unsaponifiable matter (Cd 1c-85 and Ca 6a-40). Total carotene content, expressed as $\beta$-carotene, was determined by measuring the absorbance at $446 \mathrm{~nm}$ of samples homogenized and diluted in hexane (Spectrophotometer Cary 5000, Varian, Palo Alto, CA, USA) [23]. All analyses were performed in triplicate. Acylglycerols were quantified by the Agilent 7890B gas chromatography system, following the AOCS official method (Santa Clara, CA, USA) (Cd 11b-91).

$\alpha$ - and $\beta$-carotene quantification: The chromatographic analysis was carried out in HPLC (Shimadzu, Kyoto, Japan) equipped with a quaternary pump (LC-20AD), a degasser, a UV-Vis DAD (SPD-M20A) detector, and an autoinjector (SIL-20A). The oven was set at $40{ }^{\circ} \mathrm{C}$, and chromatograms were obtained at $450 \mathrm{~nm}$. The compound separation was performed using a C30 column (Develosil, Hinode, Japan, $250 \mathrm{~mm} \times 4.6 \mathrm{~mm} ; 5 \mu \mathrm{m}$ particle size). Elution gradient was a mixture of acetonitrile and methanol $(0.05 \%$ triethylamineTEA) and Tetrahydrofuran (THF) with a flow rate of $1.2 \mathrm{~mL} \mathrm{~min}^{-1}$, in which the gradient only changed the concentrations of methanol and acetonitrile. The channels of the mobile phase were acetonitrile (A), methanol (0.05\% TEA) (B), and tetrahydrofuran (C). Gradient proceeded as follows: (C) remained isocratic at $5 \%$ during all the analysis, and all the compositions varied linearly; from $0-10 \mathrm{~min}$, (A) concentration varied from 95 to $65 \%$, and (B) channel went from 0 to $30 \%$; $10-20$ min compositions varied to $55 \%$ (A) and $40 \%$ (B) and remained isocratic up until $60 \mathrm{~min}$ of the run; 60-65 $\mathrm{min}$, the composition was set back to $65 \%$ (A) and $30 \%$ (B) and 65 . After $65 \mathrm{~min}$, (A) raised to $95 \%$ and (B) went down to $0 \%$. Samples consisted of approximately $50 \mathrm{mg}$ of crude oils diluted in $1 \mathrm{~mL}$ of acetone. The injection volume was $10 \mu \mathrm{L}$. The quantification was performed using Sigma-Aldrich $\alpha$ and $\beta$-carotene standards (St. Louis, MO, USA).

Tocols quantification: Tocopherols and tocotrienols quantification was performed by UHPLC without sample pre-treatment, as previously reported [24]. The chromatographic analysis was performed using a Waters Acquity SQD/UPLC system (Milford, MA, USA), equipped with a PDA detector, a single-quadrupole mass spectrometer system with Electrospray Ionization interface, automatic injector, a quaternary pump, and a column oven. An Acquity UPLC BEH C18 column, $1.7 \mu \mathrm{m}, 2.1 \mathrm{~mm} \times 100 \mathrm{~mm}$, was used (Milford, MA, USA). Instrument control and data acquisition were performed using the MassLynx software. Chromatographic separation was achieved by gradient elution using different proportions of Solvent A (methanol: water: ammonium hydroxide 99:1:0.1 $v / v / v$ ) and Solvent $B$ (isopropanol). The flow rate was $0.2 \mathrm{~mL} \mathrm{~min}^{-1}$ up to $6 \mathrm{~min}$, followed by $0.15 \mathrm{~mL} \mathrm{~min}^{-1}$ from 6 to $10 \mathrm{~min}$, and $0.2 \mathrm{~mL} \mathrm{~min}^{-1}$ until $15 \mathrm{~min}$. The elution gradient was as follows: $0-6 \mathrm{~min} 100 \% \mathrm{~A} ; 6.01-8 \mathrm{~min} 100 \% \mathrm{~B} ; 8.01-15 \mathrm{~min} 100 \% \mathrm{~A}$. The injection volume was $5 \mu \mathrm{L}$, and the column temperature was $25^{\circ} \mathrm{C}$. Calibration curves were performed using commercial standards of $\alpha, \beta, \gamma$, and $\delta$ tocopherols (Merck, Kenilworth, NJ, USA), and $\alpha, \gamma$, and $\delta$ tocotrienols (Chromadex, Los Angeles, CA, USA).

Main fatty acids analysis: The oleic, linoleic, and linolenic determination were performed by ${ }^{1} \mathrm{H}$ nuclear magnetic resonance (NMR). A Bruker BioSpin $\mathrm{GmbH}$ spectrometer (Billerica, MA, USA) was used, operating in a magnetic field of approximately $14 \mathrm{~T}$ with a $5 \mathrm{~mm}$ PABBO BB/19F-1H/D Z-GRD probe Z114607/0139, observing the cores from ${ }^{1} \mathrm{H}$ to $600.17 \mathrm{MHz}$. Samples were prepared using about $30-40 \mathrm{mg}$ of each oil dissolved in $2 \mathrm{~mL}$ of deuterated chloroform containing tetramethylsilane (TMS), used as a reference. The acquisition parameters were: spectral width of $12,019.2 \mathrm{~Hz}$, relaxation delay of $1 \mathrm{~s}$, number of scans 16, acquisition time of $2.7263 \mathrm{~s}$, and pulse width of $10.0400 \mathrm{~Hz}$. The experiment was conducted at $25^{\circ} \mathrm{C}$. The ${ }^{1} \mathrm{H}$ NMR spectrum was analyzed in the MestRenova $12^{\circledR}$ software (Mestrelab Research, Billerica, MA, USA), using the TMS signal at $0.00 \mathrm{ppm}$. The integrals of the signs were used to calculate concentrations. The ${ }^{1} \mathrm{H}$ NMR technique employed in this work can quantify unsaturated fatty acids, the main influence in palm oil's physical 
properties, in a more straightforward and fast way than the traditional method by gas chromatography $[21,22,25]$.

\subsection{Physical and Thermal Properties}

Density: Oil samples' densities were measured using a densimeter Rudolph Research Analytical DDM 2910 (New Jersey, NJ, USA) in the range of 20 to $80{ }^{\circ} \mathrm{C}$ at $10^{\circ} \mathrm{C}$ intervals. The standard deviations of the measurements in the densimeter after proper calibration were $1 \times 10^{-4} \mathrm{~g} \mathrm{~cm}^{-3}$.

Viscosity: Viscosities of the oils were determined using $10 \mathrm{~mL}$ samples in the range of 20 to $80^{\circ} \mathrm{C}$ at $10^{\circ} \mathrm{C}$ intervals at atmospheric pressure using an automated rheometer Brookfield LV ${ }^{\circledR}$ (Middleboro, MA, USA) equipped with a spindle SC-34. The temperature uncertainty was $0.1^{\circ} \mathrm{C}$. Approximately $12 \mathrm{~g}$ of sample was under $100 \mathrm{rpm}$ and 28 shear rate $\mathrm{s}^{-1}$ during $25 \mathrm{~min}$. The viscosity data were obtained using Rheocalc ${ }^{\circledR}$ software (Version 2.4, Brookfield Engineering Laboratories, Middleboro, MA, USA) and the calculated standard deviations were $\pm 1 \%$.

Differential scanning calorimetry (DSC): The thermal behavior of oil samples was analyzed in duplicate using a differential scanning calorimeter coupled to an automated cooling TAC-60i (Shimadzu DSC-60, Kyoto, Japan) [26]. Oil samples of 3-4 mg were placed in aluminum pans sealed and analyzed under dynamic nitrogen atmosphere at $50 \mathrm{~mL} \mathrm{~min}{ }^{-1}$. Samples were equilibrated at $80^{\circ} \mathrm{C}$, cooled at $5^{\circ} \mathrm{C} / \mathrm{min}$ to $-80^{\circ} \mathrm{C}$, and maintained at this temperature for $2 \mathrm{~min}$ to eliminate the thermal history; then, the samples were heated at $5{ }^{\circ} \mathrm{C} / \mathrm{min}$ to $80^{\circ} \mathrm{C}$, and finally cooled at $5^{\circ} \mathrm{C} / \mathrm{min}$ to $-80^{\circ} \mathrm{C}$. For oil thermal behavior, just the final heating and cooling data were considered.

Thermal gravimetric analysis (DTG): The thermogravimetric analyses of $\mathrm{HOPO}$ and APO were performed in DTG-60H equipment (Shimadzu, Kyoto, Japan). Samples of 3-4 mg were placed in platinum pans under a nitrogen flow of $50 \mathrm{~mL} \mathrm{~min}^{-1}$ and analyzed at a heating rate of $5{ }^{\circ} \mathrm{C} / \mathrm{min}$ from 30 to $460^{\circ} \mathrm{C}$. Analyses were carried out using the TA software (Shimadzu, Kyoto, Japan) [20].

\section{Results and Discussion}

\subsection{Chemical Characterization of the Oils}

Table 1 presents the physicochemical characterization of HOPO and APO. Total carotene content was 830 and $524 \mathrm{mg} / \mathrm{kg}$ for HOPO and APO, respectively, practically within the range reported for African palm oil (500-1000 mg/kg) [27]. In APO, the $\beta$-carotene concentration was $380 \mathrm{mg} / \mathrm{kg}$, while in $\mathrm{HOPO}$ it was $504 \mathrm{mg} / \mathrm{kg}$. The $\alpha$-carotene concentration was $51 \mathrm{mg} / \mathrm{kg}$ in APO and $60 \mathrm{mg} / \mathrm{kg}$ in HOPO. The concentration of $\alpha-+\beta$-carotenes combined corresponded to 69 and $82 \%$ of the total carotenes for HOPO and APO, respectively. According to the literature, all quality parameters and carotene contents met the requirement expected for palm oil [12,28].

Regarding tocopherols, HOPO and APO presented 136.4 and $167.5 \mathrm{mg} / \mathrm{kg}$ of $\alpha$ tocopherols, respectively. On the other hand, $\beta-, \gamma-$ and $\delta$-tocopherols were not detected in both oils, as usual for palm oil [12]. All classes of tocotrienols were present in $\mathrm{HOPO}$ and $\mathrm{APO}$, i.e., 128.6 and $117.1 \mathrm{mg} / \mathrm{kg}$ of $\alpha$-tocotrienol; 603.5 and $413.6 \mathrm{mg} / \mathrm{kg}$ of $\beta-/ \gamma$-tocotrienols; and 15.2 and $29.8 \mathrm{mg} / \mathrm{kg}$ of $\delta$-tocotrienol, respectively. The tocopherol/tocotrienol ratio of $\mathrm{HOPO}$ and $\mathrm{APO}$ was $18 \%$ and $29 \%$, respectively. A similar ratio of about $20 \%$ was previously reported for an oil obtained from palm trees [29]. Moreover, Mozzon et al. [12] described similar results for HOPO, in which tocotrienols were found in high incidence, and the $\alpha$-isomer was the most abundant tocopherol. Tocotrienols possess neuroprotective, anti-cancer and cholesterol-lowering properties that are often not ascribed to tocopherols [30]. 
Table 1. Physicochemical characteristics of hybrid (HOPO-E. oleifera $\times$ E. guineensis) and African (APO-E. guineensis) palm oil.

\begin{tabular}{lcc}
\hline & HOPO & APO \\
\hline ACYLGLYCEROLS $(\% W / W)$ & 0.21 & \\
MONOACYLGLYCEROL & 3.96 & 0.24 \\
DIACYLGLYCEROL & 93.73 & 4.54 \\
TRIACYLGLYCEROL & & 91.44 \\
FATTY ACIDS PROFILE $(\%)$ & 56.34 & 44.81 \\
OLEIC & 7.35 & 7.65 \\
LINOLEIC & 2.06 & 1.28 \\
LINOLENIC & $2.1 \pm 0.09$ & $3.8 \pm 0.08$ \\
FREE FATTY ACIDS $(\%$, PALMITIC) & 67.7 & 52.3 \\
IODINE VALUE $(G / 100$ G) & & $1.3 \pm 0.3$ \\
\hline UNSAPONIFIABLE MATTER (MG/G) & $2.3 \pm 0.2$ & $524 \pm 4.4$ \\
TOTAL CAROTENE (MG / KG) & $830 \pm 6$ & 51 \\
$\alpha$-CAROTENE & 60 & 380 \\
$\beta$-CAROTENE & 504 & 728.0 \\
TOCOLS (MG / KG) & 883.3 & 167.5 \\
$\alpha$-TOCOPHEROL & 136.4 & 0 \\
$\beta / \gamma$-TOCOPHEROL & 0 & 0 \\
$\delta$-TOCOPHEROL & 0 & 117.1 \\
$\alpha$-TOCOTRIENOL & 128.6 & 413.6 \\
$\beta / \gamma$-TOCOTRIENOL & 603.5 & 29.8 \\
$\delta$-TOCOTRIENOL & 15.2 &
\end{tabular}

${ }^{*}$ calculated referring to fatty acid composition previously reported by Ribeiro, Almeida, Neto, Abdelnur, and Monteiro (2018).

The unsaturated fatty acids with the highest occurrence in both oils were oleic, linoleic, and linolenic (Table 1). Those correspond to 65.6 and $53.7 \%$ of total fatty acids, corroborated by previous reports [6]. Palmitic acid is mostly responsible for completing the fatty acids composition $[5-7,12,28]$. This fatty acid composition is vital to explain the differences in vegetable oils' physical properties described hereafter. Additionally, vegetable oil composition may vary slightly with cultivation conditions, raw material maturation, and storage time. Thus, this complete chemical characterization is important to guarantee the authenticity of studied oils and register the composition at the analysis moment.

\subsection{Physicochemical Properties}

The density of palm oils measured at temperatures from 20 to $80{ }^{\circ} \mathrm{C}$ to cover a is given in Table 2. The values follow the Codex Alimentarius Standard for palm oil $\left(0.889-0.895 \mathrm{~g} \mathrm{~mL}^{-1}\right.$ at $\left.20^{\circ} \mathrm{C}\right)$ [31]. The fatty acid composition can explain the slight difference between oils' density since hybrid palm oil has about $65 \%$ unsaturated fatty acids, while African has nearly 50\% [6]. In fact, unsaturated fatty acids are denser than saturated ones [22]. Nevertheless, the differences in density found between hybrid and African oils are negligible for process design purposes. The viscosities of palm oil measured at temperatures from 40 to $80{ }^{\circ} \mathrm{C}$ are exhibited in Table 3. At temperatures lower than $40^{\circ} \mathrm{C}$, palm oils were at a semi-solid state, preventing viscosity measures. The viscosity of HOPO presented a smaller variation with temperature - a result of the higher content of unsaturated fatty acids [21].

\subsection{Thermal Analysis of the Oils}

The thermal profile of the oils, particularly the melting and crystallization events, is plotted in Figures 1 and 2. Due to the complex composition of triacylglycerols (TAGs) in the palm oil [28], several endothermic events, almost simultaneous, were observed in the heating program for both palm oils. In particular, two major endothermic events with a few sub-peaks can be identified (Figures 1 and 2 and Table 3). A similar thermal profile has been described for APO [28,32]. 
Table 2. Densities and viscosities of palm oils as a function of temperature *.

\begin{tabular}{rrrrcc}
\hline \multirow{2}{*}{ T $\left({ }^{\circ} \mathbf{C}\right)$} & \multicolumn{2}{c}{ HOPO } & \multicolumn{2}{c}{ APO } \\
\cline { 2 - 5 } & & DENSITY $\left(G / \mathrm{CM}^{3}\right)$ & VISCOSITY (CP) & DENSITY (G/CM ${ }^{3}$ ) & VISCOSITY (CP) \\
\hline 20 & 0.91369 & - & 0.91450 & - \\
30 & 0.90637 & - & 0.90680 & - \\
40 & 0.89866 & 40.19 & 0.89739 & 43.79 \\
50 & 0.88663 & 27.59 & 0.88509 & 25.19 \\
60 & 0.88396 & 20.4 & 0.88040 & 18.6 \\
70 & 0.87849 & 15.6 & 0.86810 & 13.8 \\
80 & 0.87174 & 12.0 & 0.86411 & 10.8 \\
\hline
\end{tabular}

* Standard uncertainty: density $<0.0001 \mathrm{~kg} / \mathrm{m}^{3}$, viscosity $\pm 1 \%$.

Table 3. Thermal events APO and HOPO obtained from the differential scanning calorimetry (DSC) curves.

\begin{tabular}{|c|c|c|c|c|c|c|c|}
\hline & & $\mathbf{1}^{\circ} \mathrm{PEAK}$ & $\mathrm{AD}$ & $2^{\circ} \mathrm{PEAK}$ & AD & $3^{\circ} \mathrm{PEAK}$ & $\mathrm{AD}$ \\
\hline \multirow{4}{*}{$\mathrm{APO}$} & TM & 5.32 & 0.33 & 18.68 & 0.50 & - & - \\
\hline & TRM & -30.2 UP TO 13.5 & - & 13.42 UP TO 38.67 & - & - & - \\
\hline & $\mathrm{TC}$ & -49.095 & 0.25 & 1.555 & 0.09 & 15.61 & 0.88 \\
\hline & TRC & -63.32 UP TO -39.55 & - & -39.55 UP TO 5.88 & - & 5.88 UP T0 17.89 & - \\
\hline \multirow{4}{*}{$\mathrm{HOPO}$} & TM & 2.47 & 0.33 & 11.36 & 0.83 & - & - \\
\hline & TRM & -30.0 UP TO 8.5 & - & -0.05 UP T0 33.29 & - & - & - \\
\hline & TC & -47.67 & 0.42 & -4.81 & 0.25 & 9.98 & 0.84 \\
\hline & TRC & -71.88 UP Т0 39.01 & - & -39.01 UP TO 1.82 & - & 1.82 UP T0 12.29 & - \\
\hline
\end{tabular}

$T_{m}$ is the melting point of the most ascendant peak; $T_{R m}$ is the range temperature of melting transition; $T_{c}$ is the crystallization temperature;

$\mathrm{T}_{\mathrm{Rc}}$ is the range temperature of crystallization transition; $\mathrm{AD}$ is the absolute deviation of the duplicates.

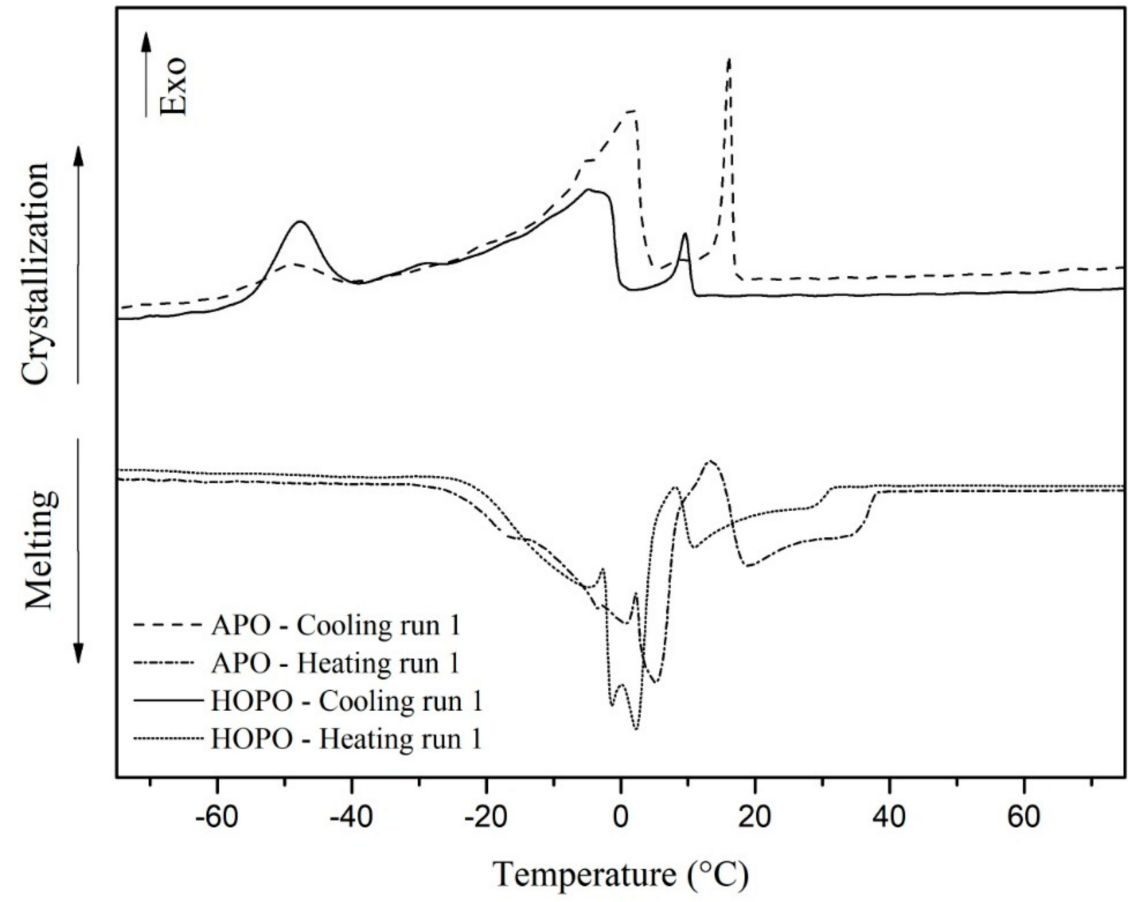

Figure 1. DSC curves in a heating and cooling program of APO and HOPO for run 1.

DSC data of heating showed the first event from $-30.2{ }^{\circ} \mathrm{C}$ to $13.5^{\circ} \mathrm{C}$ (enthalpy $39.27 \mathrm{~kJ} \cdot \mathrm{kg}^{-1}$ ) for APO and from -30.0 to $8.5^{\circ} \mathrm{C}$ (enthalpy $23.40 \mathrm{~kJ} \cdot \mathrm{kg}^{-1}$ ) for HOPO, which are related to the contribution of the unsaturated triacylglycerols melting, such as UUU or SUU (ABC = fatty acid composition of TAG, $\mathrm{U}$ unsaturated fatty acid, S saturated fatty acid) $[28,33]$. This first broad endotherm event in both palm oils also indicates the presence of OOO, POL, and PLP compounds (P palmitic, $\mathrm{O}$ oleic and L linoleic acids). Moreover, the melting peak found in $\mathrm{APO}$ at $5.48^{\circ} \mathrm{C}$ evidenced the presence of triolein compounds 
(melting temperature at $5.0^{\circ} \mathrm{C}$ ) [34]. The second endothermic event (Figure 1) is more pronounced in APO and should be related to the saturated triacylglycerols' contribution (SSS or SSU) [28].

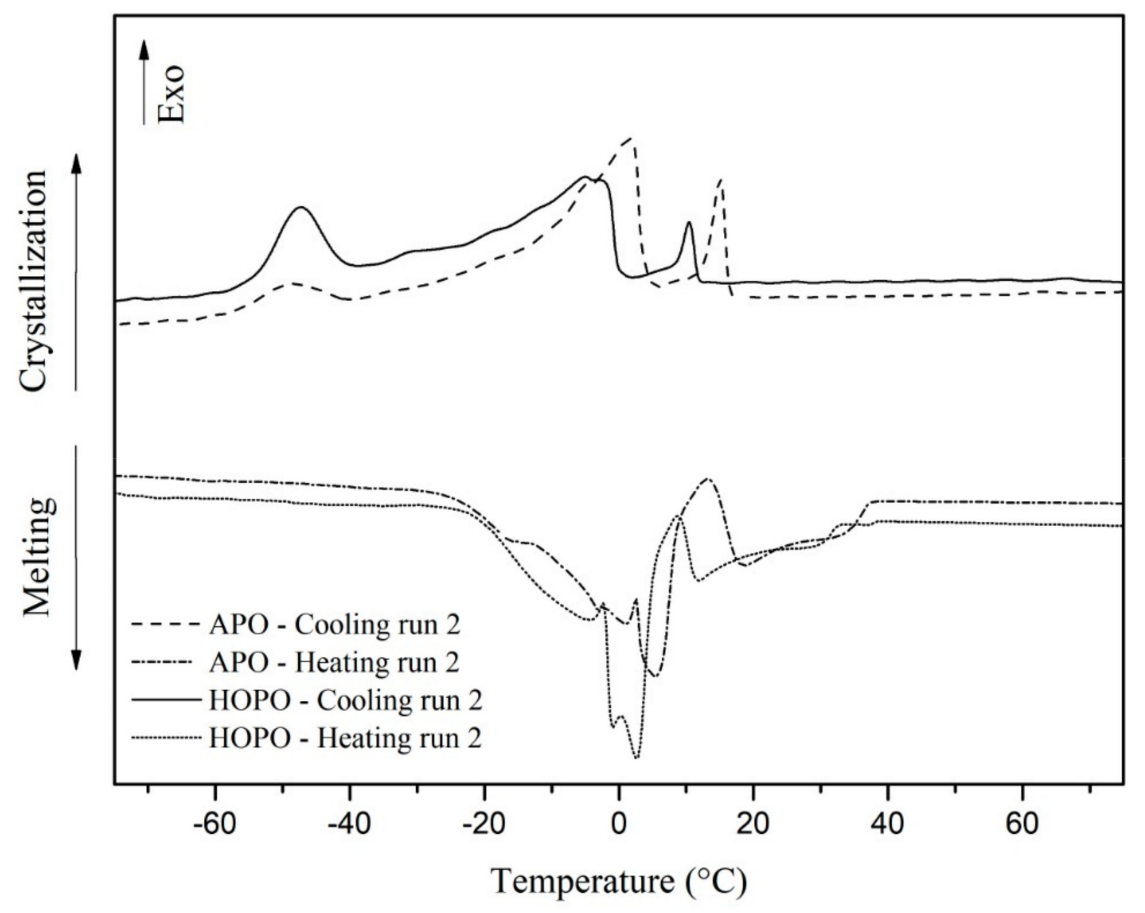

Figure 2. DSC curves in a heating and cooling program of APO and HOPO for run 2.

Table 3 shows the melting peaks and the range temperature of the endothermic events for both compounds. HOPO exhibited lower temperatures for the endothermic peaks than APO. This behavior could be related to the fact that the APO has about $50 \%$ of unsaturated fatty acids composition, while $\mathrm{HOPO}$ has around $65 \%$. In fact, unsaturated compounds present lower melting points than saturated ones $[28,32,34,35]$.

The DSC crystallization profiles for APO and HOPO obtained by the samples' cooling program are presented in Figures 1 and 2 and Table 3. APO showed three crystallization peaks (Tc), which are $-49.09^{\circ} \mathrm{C}, 1.55^{\circ} \mathrm{C}$ and $15.61^{\circ} \mathrm{C}$. A similar crystallization profile was noted for HOPO (Table 3). Additionally, in the case of APO, a third peak involving less energy, ranging from 5.88 to $17.99^{\circ} \mathrm{C}$, can be attributed to the presence of TAGs such as SSS and SSU triacylglycerols [28]. The exotherm observed at lower temperatures, which in the case of APO ranges from 5.88 to $63.32{ }^{\circ} \mathrm{C}$, and in the case of $\mathrm{HOPO}$ involves temperatures from 1.82 to $71.88^{\circ} \mathrm{C}$, is possibly related to unsaturated fatty acids (for example, UUU and SUU). These findings explain the broadest and most intense exotherm observed in HOPO, which showed a higher content of unsaturated fatty acids [33]. Similar behavior was previously reported for crude palm oil, involving two sharp peaks of crystallization obtained at temperatures slightly higher than those found here $[8,33]$.

The mass loss related to the decomposition of palm oils occurred in two steps (Figure 3). The thermal decomposition profile of both oils is similar, including a slow first step of mass loss from 180 to $300{ }^{\circ} \mathrm{C}$, and a fast second step of mass loss from 180 to $440{ }^{\circ} \mathrm{C}$, which accounts for more than $90 \%$ of the sample mass loss. Nevertheless, a difference in the kinetic of the first step of mass loss is noted among the oils (Figure 3). The first temperature range is related to the degradation of polyunsaturated fatty acids, followed by monosaturated and saturated fatty acids [36]. Even with a higher concentration of unsaturated fatty acid, HOPO is slightly more stable than APO, showing a slower first decomposition step. This thermal profile is probably due to the high amounts of antioxidant compounds, such as carotenes and tocols. The same stability improvement was reported for several commercial edible oils, such as olive, soybean, and canola [34]. 


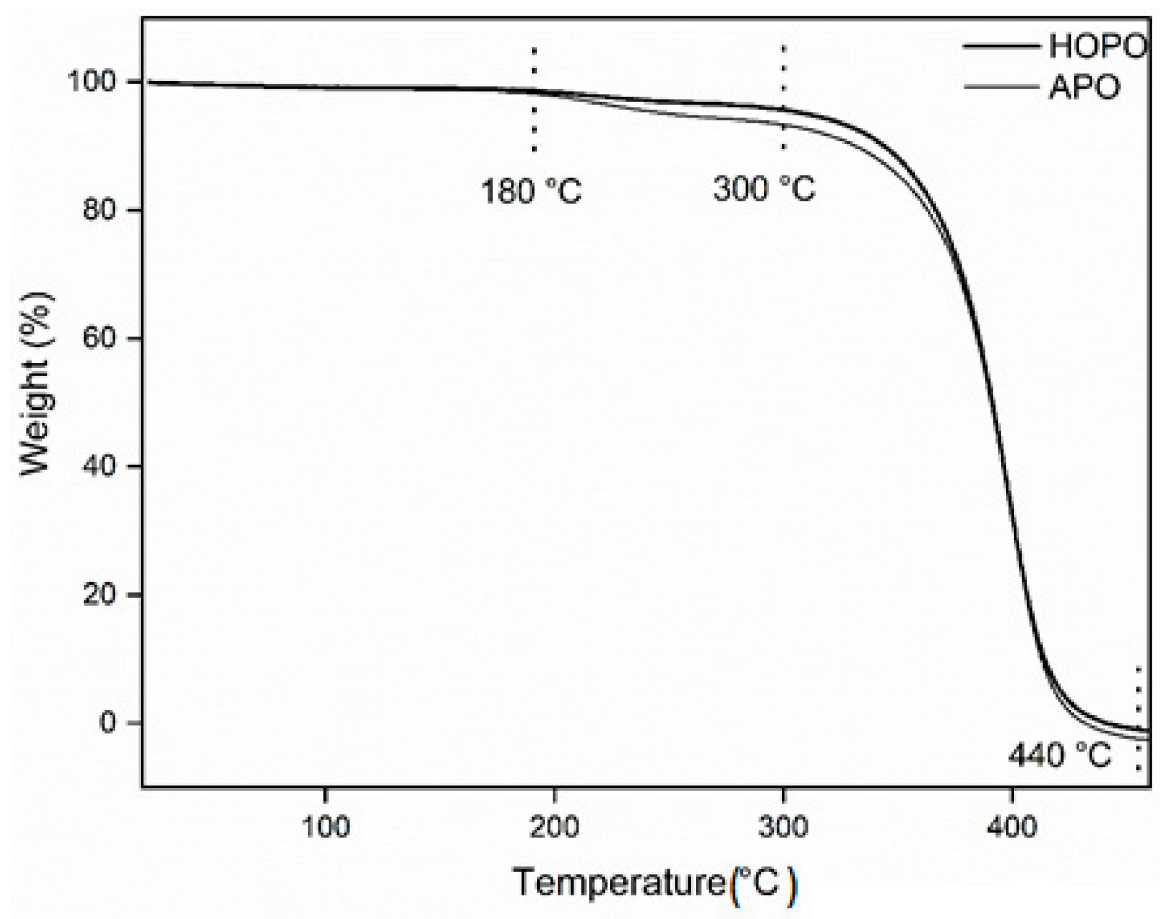

Figure 3. TGA curves of palm oil APO and HOPO.

\section{Conclusions}

This study determined the physicochemical, physical, and thermal properties of hybrid palm oil obtained from an interspecific hybrid cultivar (E. oleifera $\times$ E. guineensis), which was compared to the palm oil obtained from the African cultivar (E. guineensis). The oils presented chemical differences; however, both showed an appropriate chemical profile required for commercial exploitation. Moreover, small differences in density and viscosity were found between the oils, with no relevance for the materials' processing design. Nevertheless, the thermal analysis demonstrated that the hybrid species' oil presented distinguished melting/crystallization behavior, affecting industrial operations, such as fractionation and olein and stearin yields. Furthermore, besides the higher content of unsaturated fatty acids, HOPO was more stable than APO due to a higher antioxidant content. The results presented here are useful to establish operation conditions for processes using palm oil from hybrid oil palm, a cultivar that is arousing the industry's interest due to its resistance to pests.

Author Contributions: Conceptualization, E.S.d.A.; Methodology, E.S.d.A. formal analysis, D.d.S.D., L.C., P.A.V., R.M.d.P. and P.V.d.A.P.; Supervision, M.C.-F., K.A.S. and S.M.; Writing-original draft preparation, E.S.d.A.; Writing-Review and Editing, S.M.; Funding Acquisition, K.A.S. and S.M. All authors have read and agreed to the published version of the manuscript.

Funding: This research was funded by Conselho Nacional de Desenvolvimento Científico e Tecnológico-CNPq, grant number 421852/2018-6; 429873/2018-2; Fundação de Apoio a Pesquisa do Distrito Federal—FAPDF, grant number 224/2019; Fundação de Amparo à Pesquisa do Estado de São Paulo-FAPESP, grant number 2014/21252-0; Coordenação de Aperfeiçoamento de Pessoal de Nível Superior, grant number 001.

Institutional Review Board Statement: Not applicable.

Informed Consent Statement: Not applicable.

Acknowledgments: The authors thank Embrapa Agroenergia for providing some facilities that were necessary for the development of this work. The authors also acknowledge Denpasa for kindly donating essential material.

Conflicts of Interest: The authors declare no conflict of interest. 


\section{References}

1. United States Department of Agriculture (USDA). Oilseeds: World Markets and Trade. Available online: https://apps.fas.usda. gov / psdonline/circulars/ oilseeds.pdf (accessed on 5 January 2021).

2. Oosterveer, P. Sustainability of Palm Oil and Its Acceptance in the EU. J. Oil Palm Res. 2020, 32, 365-376. [CrossRef]

3. Sampaio, K.A.K.A.; Ayala, J.V.; Van Hoed, V.; Monteiro, S.; Ceriani, R.; Verhé, R.; Meirelles, A.J. Impact of Crude Oil Quality on the Refining Conditions and Composition of Nutraceuticals in Refined Palm Oil. J. Food Sci. 2017, 82, 1842-1850. [CrossRef]

4. Pirker, J.; Mosnier, A.; Kraxner, F.; Havlík, P.; Obersteiner, M. What Are the Limits to Oil Palm Expansion? Glob. Environ. Chang. 2016, 40, 73-81. [CrossRef]

5. Mozzon, M.; Pacetti, D.; Lucci, P.; Balzano, M.; Frega, N.G. Crude Palm Oil from Interspecific Hybrid Elaeis Oleifera $\times$ Elaeis Guineensis: Fatty Acid Regiodistribution and Molecular Species of Glycerides. Food Chem. 2013, 141, 245-252. [CrossRef] [PubMed]

6. Ribeiro, J.A.A.; Almeida, E.S.; Neto, B.A.D.; Abdelnur, P.V.; Monteiro, S. Identification of Carotenoid Isomers in Crude and Bleached Palm Oils by Mass Spectrometry. LWT Food Sci. Technol. 2018, 89, 631-637. [CrossRef]

7. Mozzon, M.; Pacetti, D.; Frega, N.G.; Lucci, P. Crude Palm Oil from Interspecific Hybrid Elaeis Oleifera $\times$ E. Guineensis: Alcoholic Constituents of Unsaponifiable Matter. J. Am. Oil Chem. Soc. 2015, 92, 717-724. [CrossRef]

8. Buscato, M.H.M.; Zaia, B.G.; De Godoi, K.R.R.; Ribeiro, A.P.B.; Kieckbusch, T.G. Modification of Palm Oil Crystallization by Phytosterol Addition as a Tool for Structuring a Low Saturated Lipid Blend. Braz. J. Chem. Eng. 2018, 35, 169-180. [CrossRef]

9. Vidoca, L.P.; Almeida, E.S.; Cardoso, M.F.; Otavio, L.; Valadares, L.F.; Monteiro, S. Extraction of Carotene from Crude Hybrid Palm Oil Using Polymeric Resin. J. Food Eng. 2020, 278, 109944. [CrossRef]

10. Hardon, J.J. Interspecific Hybrids in the Genus Elaeis II. Vegetative Growth and Yield of F1 Hybrids E. Guineensis $\times$ E. Oleifera. Euphytica 1969, 18, 380-388. [CrossRef]

11. Montoya, C.; Lopes, R.; Flori, A.; Cros, D.; Cuellar, T.; Summo, M.; Espeout, S.; Rivallan, R.; Risterucci, A.M.; Bittencourt, D.; et al. Quantitative Trait Loci (QTLs) Analysis of Palm Oil Fatty Acid Composition in an Interspecific Pseudo-Backcross from Elaeis Oleifera (H.B.K.) Cortés and Oil Palm (Elaeis Guineensis Jacq.). Tree Genet. Genomes 2013, 9, 1207-1225. [CrossRef]

12. Mozzon, M.; Foligni, R.; Mannozzi, C. Current Knowledge on Interspecific Hybrid Palm Oils as Food and Food Ingredient. Foods 2020, 9, 631. [CrossRef] [PubMed]

13. Basiron, Y. Palm Oil. In Bailey's Industrial Oil and Fat Products; Shahidi, F., Ed.; John Wiley \& Son: New York, NY, USA, 2005; Volume 2, pp. 333-430.

14. Che Man, Y.B.; Haryati, T.; Ghazali, H.M.; Asbi, B.A. Composition and Thermal Profile of Crude Palm Oil and Its Products. J. Am. Oil Chem. Soc. 1999, 76, 237-242. [CrossRef]

15. Hishamuddin, E.; Nagy, Z.K.; Stapley, A.G.F. Thermodynamic Analysis of the Isothermal Fractionation of Palm Oil Using a Novel Method for Entrainment Correction. J. Food Eng. 2020, 273, 109806. [CrossRef]

16. Mancini, A.; Imperlini, E.; Nigro, E.; Montagnese, C.; Daniele, A.; Orrù, S.; Buono, P. Biological and Nutritional Properties of Palm Oil and Palmitic Acid: Effects on Health. Molecules 2015, 20, 17339-17361. [CrossRef]

17. West, R.; Rousseau, D. Tripalmitin-Driven Crystallization of Palm Oil: The Role of Shear and Dispersed Particles. JAOCS J. Am. Oil Chem. Soc. 2020, 97, 989-999. [CrossRef]

18. Gibon, V.; Danthine, S. Systematic Investigation of Co-Crystallization Properties in Binary and Ternary Mixtures of Triacylglycerols Containing Palmitic and Oleic Acids in Relation with Palm Oil Dry Fractionation. Foods 2020, 9, 1891. [CrossRef] [PubMed]

19. Wan Nik, W.B.; Ani, F.N.; Masjuki, H.H. Thermal Stability Evaluation of Palm Oil as Energy Transport Media. Energy Convers. Manag. 2005, 46, 2198-2215. [CrossRef]

20. Ceriani, R.; Paiva, F.R.; Goncalves, C.B.; Batista, E.A.C.; Meirelles, A.J.A. Densities and Viscosities of Vegetable Oils of Nutritional Value. J. Chem. Eng. Data 2008, 53, 1846-1853. [CrossRef]

21. Freitas, S.V.D.; e Silva, F.A.; Pastoriza-Gallego, M.J.; Piñeiro, M.M.; Lima, A.S.; Coutinho, J.A.P. Measurement and Prediction of Densities of Vegetable Oils at Pressures up to 45 MPa. J. Chem. Eng. Data 2013, 58, 3046-3053. [CrossRef]

22. AOCS. Methods and Recommended Practices of the American Oil Chemists' Society; America Oil Chemists' Society: Champaign, IL, USA, 1998.

23. Siew, W.L.; Tang, T.S.; Tan, Y.A. PORIM: Test Methods; Palm Oil Research Institute of Malaysia: Kuala Lumpur, Malaysia, 1995.

24. Ansolin, M.; de Souza, P.T.; de Almeida Meirelles, A.J.; Batista, E.A.C. Tocopherols and Tocotrienols: An Adapted Methodology by UHPLC/MS Without Sample Pretreatment Steps. Food Anal. Methods 2017, 10, 2165-2174. [CrossRef]

25. Vigli, G.; Philippidis, A.; Spyros, A.; Dais, P. Classification of Edible Oils by Employing 31P and 1H NMR Spectroscopy in Combination with Multivariate Statistical Analysis. A Proposal for the Detection of Seed Oil Adulteration in Virgin Olive Oils. J. Agric. Food Chem. 2003, 51, 5715-5722. [CrossRef] [PubMed]

26. De Graef, V.; Dewettinck, K.; Verbeken, D.; Foubert, I. Rheological Behavior of Crystallizing Palm Oil. Eur. J. Lipid Sci. Technol. 2006, 108, 864-870. [CrossRef]

27. España, M.D.; Mendonça, S.; Carmona, P.A.O.; Guimarães, M.B.; da Cunha, R.N.V.; Souza, M.T.; Cunha, R.N.V.; Souza, M.T Chemical Characterization of the American Oil Palm from the Brazilian Amazon Forest. Crop Sci. 2018, 58, 1982-1990. [CrossRef]

28. Braipson-Danthine, S.; Gibon, V. Comparative Analysis of Triacylglycerol Composition, Melting Properties and Polymorphic Behavior of Palm Oil and Fractions. Eur. J. Lipid Sci. Technol. 2007, 109, 359-372. [CrossRef]

29. Gibon, V.; De Greyt, W.; Kellens, M. Palm Oil Refining. Eur. J. Lipid Sci. Technol. 2007, 109, 315-335. [CrossRef] 
30. Sen, C.K.; Khanna, S.; Roy, S. Tocotrienols: Vitamin E beyond Tocopherols. Life Sci. 2006, 78, 2088-2098. [CrossRef] [PubMed]

31. Codex Alimentarius. Codex Standard For Named Vegetable Oils CXS 210-1999. Available online: http://www.fao.org/3/y277 4e/y2774e04.htm (accessed on 5 January 2021).

32. Danthine, S.; De Clercq, N.; Dewettinck, K.; Gibon, V. Monitoring Batch Lipase Catalyzed Interesterification of Palm Oil and Fractions by Differential Scanning Calorimetry. J. Therm. Anal. Calorim. 2014, 115, 2219-2229. [CrossRef]

33. De Oliveira, G.M.; Badan Ribeiro, A.P.; dos Santos, A.O.; Cardoso, L.P.; Kieckbusch, T.G. Hard Fats as Additives in Palm Oil and Its Relationships to Crystallization Process and Polymorphism. LWT Food Sci. Technol. 2015, 63, 1163-1170. [CrossRef]

34. Kodali, D.R. Trans Fats: Health, Chemistry, Functionality, and Potential Replacement Solutions. In Trans Fats Replacement Solutions; Kodali, D.R., Ed.; AOCS Press: Urbana, IL, USA, 2014; pp. 1-39. [CrossRef]

35. Foon, C.S.; Liang, Y.C.; Mat Dian, N.L.H.; May, C.Y.; Hock, C.C.; Ngan, M.A. Crystallisation and Melting Behavior of Methyl Esters of Palm Oil. Am. J. Appl. Sci. 2006, 3, 1859-1863. [CrossRef]

36. Castro, R.I.; Gallego, J.; García, M.F.; Marican, A.; Forero-Doria, O. Thermal Study and Composition of Edible Oils Combined by TG/DTG Analysis through Predictive Statistical Model. J. Therm. Anal. Calorim. 2020, 1-8. [CrossRef] 